\title{
Burr hole craniostomy versus minicraniotomy in chronic subdural hematoma: a comparative cohort study
}

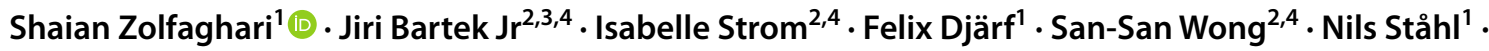 \\ Asgeir S. Jakola ${ }^{5,6,7} \cdot$ Henrietta Nittby Redebrandt ${ }^{1}$
}

Received: 23 March 2021 / Accepted: 7 June 2021 / Published online: 30 July 2021

(c) The Author(s) 2021

\begin{abstract}
Background Chronic subdural hematoma (CSDH) is one of the most common neurosurgical diseases. In surgical management of CSDH, there is a lack of standardized guidelines concerning surgical techniques and a lack of consensus on which technique(s) are optimal. Neurosurgical centers have shown a wide variation in surgical techniques. The purpose of this study was to compare two different surgical techniques, one burr hole craniostomy with an active subgaleal drain (BHC) and minicraniotomy with a passive subdural drain (MC).

Methods We conducted a multicenter retrospective cohort study at two neurosurgical centers in Sweden which included patients with unilateral CSDHs that received surgical treatment with either BHC or MC. The primary outcomes in comparison of the techniques were 30-day mortality, recurrence rate, and complications according to the Landriel Ibañez grading system for complications.

Results A total of 1003 patients were included in this study. The BHC subgroup included 560 patients, and the MC subgroup included 443 patients. A 30-day mortality when comparing BHC (2.3\%) and MC (2.7\%) was similar $(\mathrm{p}=0.701)$. Comparing recurrence rate for BHC $(8.9 \%)$ and MC $(10.8 \%)$ showed no significant difference $(\mathrm{p}=0.336)$. We found that medical complications were significantly more common in the MC group $(\mathrm{p}=0.001)$. Surgical complications (type IIb) was also associated with the MC group $(n=10, p=0.003)$. Out of the 10 patients with type IIb complications in the MC group, 8 had postoperative acute subdural hematomas.

Conclusions BHC was comparable to MC concerning 30-day mortality rate and recurrence rates. We did, however, find that MC was significantly associated with medical complications and serious surgical postoperative complications.
\end{abstract}

Keywords CSDH $\cdot$ Surgical method $\cdot$ Complications $\cdot$ Recurrence $\cdot$ Outcome

The following paper has been submitted for presentation as an abstract poster at the EANS congress 2021 in Hamburg

This article is part of the Topical Collection on Brain trauma.

Shaian Zolfaghari

Shaian.zolfaghari@med.lu.se

1 Department of Neurosurgery, Institution of Clinical Sciences, Lund University, Lund, Sweden

2 Department of Neurosurgery, Karolinska University Hospital, Stockholm, Sweden

3 Department of Neurosurgery, Rigshospitalet, Copenhagen, Denmark

4 Department of Clinical Neuroscience and Medicine, Karolinska Institutet, Stockholm, Sweden
Abbreviations

CSDH Chronic subdural hematoma

BHC One burr hole craniostomy with active subgaleal drain

MC Minicraniotomy with passive subdural drain

CCI Charlson comorbidity index

5 Department of Neurosurgery, St. Olavs Hospital, Trondheim, Norway

6 Department of Neurosurgery, Sahlgrenska University Hospital, Gothenburg, Sweden

7 Department of Clinical Neuroscience, Institute of Neuroscience and Physiology, University of Gothenburg, Sahlgrenska Academy, Gothenburg, Sweden 


\section{Introduction}

Chronic subdural hematoma (CSDH) is one of the most common neurosurgical diseases with a reported incidence of 8 to 14 per 100,000 person-years [14]. The incidence is expected to rise significantly, projecting the surgical evacuation of CSDH to become the most common neurosurgical procedure by 2030 [3]. The disease primarily affects the elderly population, and people with risk factors such as trauma, antithrombotic medication, anticoagulants, and alcohol abuse have been identified [10,11, 14]. The increasing incidence already has a socio-economic impact on current healthcare systems, which together with recurrence rates estimated around 10-20\% and a non-negligible surgical morbidity adds to the complexity of CSDH management [1, $4,14]$. Optimizing surgical treatment can help in lowering morbidity and recurrence rates, as well as minimizing the socio-economic impact.

The most common surgical technique is considered to be the burr hole craniostomy (BHC) where 1-2 burr holes are drilled. In the setting of 2 burr holes, they are drilled 5-8 cm apart to allow for effective irrigation of the hematoma [22]. An alternative to this is the minicraniotomy (MC) where 2-3 burr holes are drilled in close vicinity and joined together into a larger bone defect followed by irrigation. Previous data has shown that $\mathrm{BHC}$ has the best cure-to-complication ratio [29]. Furthermore, data on BHC have not been able to prove a difference in outcome when comparing 1 and 2 burr holes when performing BHC; there is however limited data on outcomes when performing BHC with one burr hole under local anesthesia [5, 25].

It is considered the standard of care today to insert a postoperative drain to allow for further drainage of hematoma as it has shown to decrease mortality and reduce the risk of recurrence of CSDH [23]. Initial evidence was shown for passive subdural drains, but lately evidence has shown less risk of recurrence when using an active subgaleal drain compared to the passive subdural drain [24].

The aim of this study was to assess burr hole craniostomy with active subgaleal drain in comparison to minicraniotomy with passive subdural drain with an emphasis on recurrence rate, mortality, and risk of complications.

\section{Methods and materials}

\section{Study cohort}

The following multicenter retrospective comparative cohort study took place at Scania University Hospital and Karolinska University Hospital. All patients over the age of 18 diagnosed with a surgically evacuated CSDH were eligible for the study. The study had the following exclusion criteria: bilateral CSDHs, cerebral shunts, simultaneous intracranial hemorrhages, and patients with permanent residency outside of Sweden. The patients included from Scania University Hospital were treated between 2012 and 2016, while the patients included from Karolinska University Hospital were treated between 2006 and 2014. During the time periods, the surgical techniques and management of CSDH were not altered at either center. A total of 1003 patients were included in this retrospective cohort study.

\section{Surgical techniques}

Patients were operated and managed with the following surgical techniques denoted as methods 1 and 2. Method 1 (i) was the standard surgical technique for evacuation of CSDH at Scania University Hospital. Method 2 (ii) was the standard surgical technique for evacuation of CSDH at Karolinska University Hospital. Surgeries were always to be conducted with local anesthesia unless special circumstances indicated the need of general anesthesia. In both centers, perioperative usage of antibiotics was administered prior to the initiation of surgery.

i. Two or three burr holes combined into a minicraniotomy. The hematoma was evacuated with irrigation after which a passive subdural drain was placed in the subdural space for $24 \mathrm{~h}$, while the patients were immobilized in bed. The passive drain did not have any active suction but rather functioned by natural pressure gradients.

ii. Singular burr hole. The hematoma was evacuated with irrigation after which an active subgaleal drain was placed in the subgaleal space for $24 \mathrm{~h}$, while the patients were immobilized in bed [24]. The active drain used active suction to drain the remaining fluids from the subdural space.

\section{Variables}

The data from this study was retrieved using the electric medical journal systems at both hospitals and the respective radiological image databases for both hospitals. Baseline characteristics for this study included age, gender (male/ female), Charlson comorbidity index (CCI) variables (index which predicts mortality based on weighted comorbidities) [18], preoperative Glasgow Coma Scale (GCS) score, antithrombotic medications, use of vitamin $\mathrm{K}$ antagonist (VKA), and radiological densities of the hematomas on computed tomography scans graded as the largest portion of the hematoma being hypodense, isodense, hyperdense, or with mixed densities. All patients underwent a CT of the 
head preoperatively. No postoperative head CTs were routinely performed unless clinically indicated.

Radiological data was retrieved in the form of midline shift $(\mathrm{mm})$ and largest hematoma diameter in the axial plane (mm). Surgical data was retrieved in the form of the type of anesthesia used (local with sedation or general anesthesia), drainage system duration, recurrence rate (defined as new evacuation of CSDH on the same side within 3 months of the initial evacuation), and mortality at 30 days and 1 year past surgical date. Complications were registered according to Landriel Ibañez (classification system for complications after neurosurgical procedures) [15]. Complications were defined as any deviation from the normal postoperative course occurring within 30 days of surgery. Reoperation was not registered as a complication in our study.

\section{Statistical analysis}

All statistical analyses were performed using IBM SPSS Statistics for Windows, version 25.0, Armonk, NY, IBM Corporation. Descriptive statistics including measures such as frequency (n), percentages, mean, and median were employed to further describe subgroup characteristics. Univariate (independent samples t-test and Mann-Whitney), Chi-squared, Fisher's exact test, and Cox regression were performed to assess the endpoints of this study. Alpha level of significance was defined as $\mathrm{P}$-value $<0.05$ in all analyses. Adjusted residuals $>2$ was considered to indicate a significance level $<0.05$.

\section{Results}

\section{Baseline characteristics}

A total of 1003 patients were included in our study cohort from two neurosurgical centers. A summary of the baseline characteristics can be found in Table 1 . The majority of the study cohort consisted of males $(68.2 \%)$ and were evenly distributed between the two treatment groups. The mean age of the study population at the time of diagnosis was 75 years. The two treatment groups had a similar distribution of underlying comorbidities defined as CCI $>1$ point (33.9\% vs $28.7 \%, \mathrm{p}=0.075$ Mann-Whitney).

Antithrombotic treatment was evenly represented in both treatment groups. Anticoagulation in the form of VKA was more present in the MC group (20.5\% vs $14.8 \%$, $\mathrm{p}=0.020$ Mann-Whitney). The preoperative GCS scores were similar in both groups with a median of 15 and with most scores between 13 and 15 in both treatment groups (89.8\% and $92.1 \%)$.

Data concerning surgical characteristics and outcome was also collected for the study cohort (Table 2). The mean hematoma diameter for the study cohort was $22.5 \mathrm{~mm}$ with comparable diameters in both treatment groups. The midline shift was however found to be significantly larger in the MC group $(p=0.013)$. Most patients were operated in local anesthesia with light sedation ( $97 \%$ in the BHC group vs $88.3 \%$ in the MC group). The drainage systems
Table 1 Baseline characteristics of the study population. Variables are stratified for the two surgical methods

\begin{tabular}{|c|c|c|}
\hline Variable, No. (\%) & $\begin{array}{l}\text { BHC with active subgaleal } \\
\text { drain } \mathrm{N}=560 \\
\text { No. }(\%)\end{array}$ & $\begin{array}{l}\text { Minicraniotomy with } \\
\text { passive subdural drain } \\
\mathrm{N}=443 \\
\text { No. }(\%)\end{array}$ \\
\hline Mean age (years) $\pm S D$ & $74.1 \pm 12.9$ & $75.6 \pm 11.6$ \\
\hline Male, $n=684(68.2)$ & $369(65.9)$ & $315(71.1)$ \\
\hline \multicolumn{3}{|l|}{ Charlson comorbidity index } \\
\hline Score over $1, \mathrm{n}=317$ (31.6) & $190(33.9)$ & $127(28.7)$ \\
\hline Antithrombotic treatment, $\mathrm{n}=251(25.0)$ & $142(25.4)$ & $109(24.6)$ \\
\hline Vitamin K antagonist, $\mathrm{n}=174$ (17.3) & $83(14.8)$ & $91(20.5)$ \\
\hline \multicolumn{3}{|l|}{ Preoperative GCS score* } \\
\hline $13-15, \mathrm{n}=911(90.8)$ & $503(89.8)$ & $408(92.1)$ \\
\hline $9-12, n=47(4.7)$ & $30(5.4)$ & $17(3.8)$ \\
\hline $3-8, n=24(2.4)$ & $14(2.5)$ & $10(2.3)$ \\
\hline \multicolumn{3}{|l|}{ CT hematoma density** } \\
\hline Hyperdense, $\mathrm{n}=215$ (21.4) & $134(23.9)$ & $81(18.3)$ \\
\hline Isodense, $n=429(42.8)$ & $257(45.9)$ & $172(38.8)$ \\
\hline Hypodense, $\mathrm{n}=335$ (33.4) & $159(28.4)$ & $176(39.7)$ \\
\hline Mixed densities, $\mathrm{n}=19$ (1.9) & $10(1.8)$ & $9(2.0)$ \\
\hline
\end{tabular}

SD: Standard deviation

*21 patients with missing GCS values

** 5 patients with missing characterization of CT hematoma density 
Table 2 Surgical characteristics and outcome data of the study population. The data in the following table is stratified for the two surgical methods

\begin{tabular}{|c|c|c|}
\hline $\begin{array}{l}\text { Variable } \\
\text { No. (\%) }\end{array}$ & $\begin{array}{l}\text { BHC with active subgaleal } \\
\text { drain } \\
N=560 \\
\text { No. }(\%)\end{array}$ & $\begin{array}{l}\text { Minicraniotomy with } \\
\text { passive subdural drain } \\
\mathrm{N}=443 \\
\text { No. }(\%)\end{array}$ \\
\hline Mean midline shift $(\mathrm{mm}) \pm \mathrm{SD}$ & $8.8 \pm 4.2$ & $9.5 \pm 4.2$ \\
\hline Mean axial hematoma diameter $(\mathrm{mm}) \pm \mathrm{SD}$ & $22.5 \pm 6.4$ & $22.4 \pm 5.6$ \\
\hline Local anesthesia with light sedation, $\mathrm{n}=934$ (93.1) & $543(97.0)$ & $391(88.3)$ \\
\hline Mean time with drainage system (days) \pm SD & $1.0 \pm 0.06$ & $1.2 \pm 0.44$ \\
\hline Reoperated within 3 months after primary evacuation, $\mathrm{n}=98$ & $50(8.9)$ & $48(10.8)$ \\
\hline 30-day mortality, $\mathrm{n}=25(2.5)$ & $13(2.3)$ & $12(2.7)$ \\
\hline 1-year mortality, $\mathrm{n}=112$ (11.2) & $70(12.5)$ & $42(9.5)$ \\
\hline Complications according to Ibañez, $\mathrm{n}=131$ (13.1) & $35(6.3)$ & $96(21.7)$ \\
\hline Grade Ia: complication requiring no drug treatment & $5(0.90)$ & $21(4.7)$ \\
\hline Grade Ib: complication requiring drug treatment & $17(3.0)$ & $50(11.3)$ \\
\hline Grade IIa: complication requiring intervention without general anesthesia & $5(0.9)$ & $6(1.4)$ \\
\hline Grade IIb: complication requiring intervention with general anesthesia & $1(0.2)$ & $10(2.3)$ \\
\hline Grade IIIa: complication involving single organ failure and ICU care & $2(0.4)$ & $1(0.20)$ \\
\hline Grade IIIb: complication involving multiple organ failure and ICU care & $0(0.0)$ & $0(0.0)$ \\
\hline Grade IV: complication resulting in death & $5(0.9)$ & $8(1.8)$ \\
\hline
\end{tabular}

SD: Standard deviation

were inserted for similar durations (1.0 in the BHC group vs 1.2 days in the MC group).

\section{Recurrence rates in the surgical treatment models}

The recurrence rates for the entire study population were $9.8 \%(n=98)$. Recurrence rate was $10.8 \%(n=48)$ for patients operated with MC and $8.9 \%(n=50)$ for patients operated with BHC. The odds ratio for reoperation after treatment with $\mathrm{MC}$ was 1.24 and non-significant as compared to surgery with $\mathrm{BHC}(\mathrm{p}=0.336,95 \% \mathrm{CI} 0.82-1.88)$.

\section{Complication rates in the surgical treatment models}

Complications were categorized by using the Landriel Ibañez system for complications. The study cohort had a total of 131 complications (13.1\%) with $35(6.3 \%)$ in patients who had undergone treatment with BHC. The remaining 96 complications (21.7\%) were associated with MC (Table 2).

Complications were analyzed in regard to the two treatment groups with a statistically significant difference $(\mathrm{p}<0.001)$. The analysis did however not give sufficient insight into the subgroups, and thus, post hoc testing was used yielding significant adjusted residual values $(>2)$ for Ibañez types Ia, Ib, and IIb (Table 3).

Table 3 Univariable analysis of complications associated with the two treatment groups. All tests were done with Fisher's exact test

\begin{tabular}{|c|c|c|c|c|c|}
\hline Complication type & $\begin{array}{l}\text { BHC with active sub- } \\
\text { galeal drain } \mathrm{N}=560 \\
(\%)\end{array}$ & $\begin{array}{l}\text { Minicraniotomy with pas- } \\
\text { sive subdural drain } \mathrm{N}=443 \\
(\%)\end{array}$ & P-value & CI $95 \%$ & $\begin{array}{l}\text { Adjusted } \\
\text { residual } \\
\text { value }\end{array}$ \\
\hline Grade Ia: complication requiring no drug treatment & $5(0.90)$ & $21(4.7)$ & $0.001 *$ & $2.1-14.8$ & 3.8 \\
\hline Grade Ib: complication requiring drug treatment & $17(3.0)$ & $50(11.3)$ & $0.001 *$ & $2.3-7.2$ & 5.2 \\
\hline $\begin{array}{l}\text { Grade IIa: complication requiring intervention without } \\
\text { general anesthesia }\end{array}$ & $5(0.9)$ & $6(1.4)$ & 0.550 & $0.5-5.0$ & 0.7 \\
\hline $\begin{array}{l}\text { Grade IIb: complication requiring intervention with } \\
\text { general anesthesia }\end{array}$ & $1(0.2)$ & $10(2.3)$ & $0.003 *$ & $1.6-101.2$ & 3.1 \\
\hline $\begin{array}{l}\text { Grade IIIa: complication involving single organ failure } \\
\text { and ICU care }\end{array}$ & $2(0.4)$ & $1(0.2)$ & 1.000 & $0.1-7.0$ & -0.4 \\
\hline Grade IV: complication resulting in death & $5(0.9)$ & $8(1.8)$ & 0.263 & $0.7-6.3$ & 1.3 \\
\hline
\end{tabular}

*Significant p-value 
The complication types were compared between the treatment groups with exception for Ibañez IIIb where no cases were recorded. We identified complications categorized as Ibañez Ia, Ib, and IIb to have a significantly increased odds ratio of being present in the treatment group of MC (Table 3). As was previously indicated to us by the abnormally high adjusted residual values.

Detailed analysis of Ibañez IIb complications in the MC group revealed that out of the 10 reported IIb complications, 8 had postoperative acute subdural hematomas, 1 postoperative epidural hematoma, and 1 subdural empyema (Table 4).

\section{0-day mortality rate in the surgical treatment models}

Mortality was calculated from the time of surgery to the time of death. A 30-day and 1-year mortality was registered for all study patients. A 30-day mortality for the study cohort was found to be $2.5 \%(n=25)$ with even distribution between the two treatment models ( $\mathrm{p}=0.696$, Mann-Whitney). This was further tested in a survival function test. The hazard ratio for mortality at 30-day post-surgery with $\mathrm{MC}$ was 1.17 and non-significant as compared to BHC ( $\mathrm{p}=0.701,95 \% \mathrm{CI}$ 0.53-2.56, Cox regression) (Fig. 1).

Table 4 Characterization of Ibañez IIb complications in the MC subgroup

\begin{tabular}{ll}
\hline Type of IIb complication & $\begin{array}{l}\text { Total compli- } \\
\text { cations } \mathrm{n}=10 \\
(\%)\end{array}$ \\
\hline Postoperative acute subdural hematoma & $8(80.0)$ \\
Postoperative epidural hematoma & $1(10.0)$ \\
Postoperative subdural empyema & $1(10.0)$ \\
\hline
\end{tabular}

\section{Discussion}

In this retrospective cohort study involving patients with unilateral CSDH undergoing surgery with two different techniques, BHC with active subgaleal drain or MC with passive subdural drain, we found no significant differences in outcome concerning mortality or recurrence. However, there was a significant difference in reported complications favoring $\mathrm{BHC}$ with active subgaleal drain compared to MC with passive subdural drain.

The recurrence rate in our study was in line with previously reported recurrence rates for CSDHs. When comparing our two surgical methods, we were not able to identify a significant difference in recurrence rate. Previous studies have highlighted the benefits of a MC due to better visualization and access to the hematoma and membranes [27]. The MC has been theorized to be better suited for recurrent CSDHs but also to prevent recurrence in the first place. There are however other studies with no major differences in outcomes such as recurrence when comparing MC to BHC $[16,20]$. There is also data supporting the use of only one burr hole instead of two burr holes with similar results $[5,23,28]$. Regarding drainage techniques, initial studies proved the efficacy of subdural drains [23], whereas subsequent studies on active subgaleal drains seem to be of similar effectiveness without the risk of misplacement in the brain parenchyma. $[9,12,13,24,26]$.

In our study, there was no difference in mortality between the groups. The 1-year mortality rate in our study cohort was $11.2 \%$, which is in line with previous studies $[19,30]$. This contrasts the 1-year mortality rate for the general Swedish population between 75 and 79 years of age being approximately 3\% [6]. We thus confirm that CSDH seems to be a sentinel health event $[8,14,17]$.
Fig. 1 Survival function curve displaying the non-significant difference in 30-day mortality between the two treatment groups

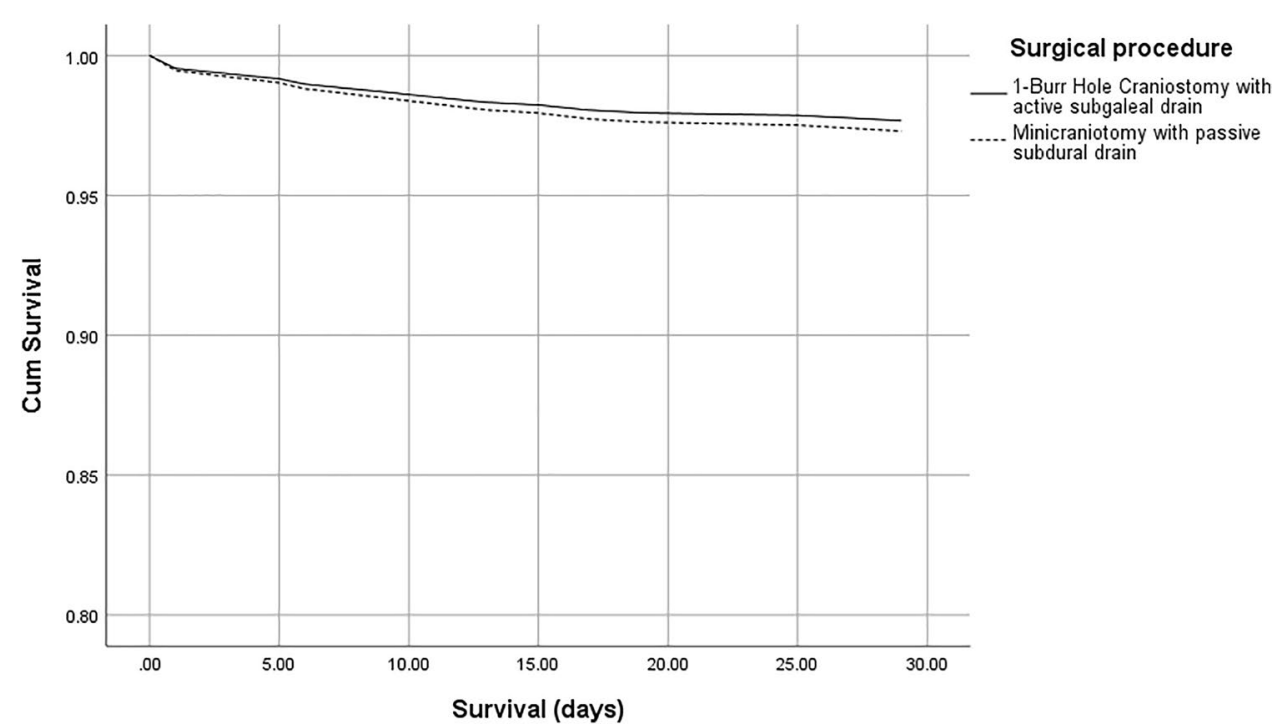


In our study, we found a higher rate of complications associated with MC. The rate of Ia and Ib complications (medical complications) in the MC group in our study was $16 \%$, which is in line with previous studies [21, 27]. MC was also associated with significantly more type IIb complications. Previous studies have found an increased rate of serious complications and morbidity when operating with a craniotomy $[7,16]$. However, it is important to note that those studies are referring to a more invasive technique compared to MC. Van der Weken et al. specifically studied MC but could not verify that the technique was associated with serious surgical complications [27].

The study is inherently limited by the retrospective study design. In this study, we chose to include unilateral hematomas, which are reflected in the relatively low recurrence rates. Bilateral CSDH's are associated with an increased risk of recurrence $[2,31]$. The study is limited by the dyssynchronous time periods between the two centers, even though we have no clear indications that this would affect the results regarding recurrence or complications. The strength of the study is the relatively large study population and a health care system where no patients with CSDH are treated in private clinics, reducing the risk of selection bias. It also enables us to register complications, especially severe complications requiring surgery, since no surgical complications will be handled outside the neurosurgical departments at our hospitals.

\section{Conclusion}

In this retrospective comparative cohort study, we found that the less invasive BHC technique holds at least equivalent effectiveness to MC. We also found that surgical evacuation by $\mathrm{MC}$ was significantly associated with medical complications as well as surgical complications, including postoperative acute subdural hematomas indicating a better safety profile when using the $\mathrm{BHC}$ technique.

Acknowledgements We are grateful to Suhayb Ehsaan Ilaahi for language editing.

Funding Open access funding provided by Lund University. This research was supported by Region Skåne ALF Fund [2019-YF0009].

\section{Declarations}

Ethics approval All procedures performed in studies involving human participants were in accordance with the ethical standards of the institutional and/or national research committee and with the 1964 Helsinki Declaration and its later amendments or comparable ethical standards. The following study has been approved by the regional ethics committee on the respective study sites with ethical permit numbers EPN 2017/247 and EPN 2013/591-31/1.
Informed consent For this type of study, formal consent is not required.

Conflict of interest The authors declare no competing interests.

Open Access This article is licensed under a Creative Commons Attribution 4.0 International License, which permits use, sharing, adaptation, distribution and reproduction in any medium or format, as long as you give appropriate credit to the original author(s) and the source, provide a link to the Creative Commons licence, and indicate if changes were made. The images or other third party material in this article are included in the article's Creative Commons licence, unless indicated otherwise in a credit line to the material. If material is not included in the article's Creative Commons licence and your intended use is not permitted by statutory regulation or exceeds the permitted use, you will need to obtain permission directly from the copyright holder. To view a copy of this licence, visit http://creativecommons.org/licenses/by/4.0/.

\section{References}

1. Almenawer SA, Farrokhyar F, Hong C, Alhazzani W, Manoranjan B, Yarascavitch B, Arjmand P, Baronia B, Reddy K, Murty N, Singh S (2014) Chronic subdural hematoma management: a systematic review and meta-analysis of 34,829 patients. Ann Surg 259(3):449-457

2. Andersen-Ranberg NC, Poulsen FR, Bergholt B, Hundsholt T, Fugleholm K (2017) Bilateral chronic subdural hematoma: unilateral or bilateral drainage? J Neurosurg 126(6):1905-1911

3. Balser D, Farooq S, Mehmood T, Reyes M, Samadani U (2015) Actual and projected incidence rates for chronic subdural hematomas in United States veterans administration and civilian populations. J Neurosurg 123(5):1209-1215

4. Bartek J Jr, Sjåvik K, Kristiansson H, Ståhl F, Fornbe I, Förander P, Jakola AS (2017) Predictors of recurrence and complications after chronic subdural hematoma surgery: a population-based study. World Neurosurg 106:609-614

5. Belkhair S, Pickett G (2013) One versus double burr holes for treating chronic subdural hematoma meta-analysis. Can J Neurol Sci 40(1):56-60

6. Central Bureau of Statistics, Sweden. Statistics on death and population size in Sweden. https://www.statistikdatabasen.scb. se/pxweb/sv/ssd/. Accessed Mar 8, 2021.

7. Ducruet AF, Grobelny BT, Zacharia BE, Hickman ZL, DeRosa PL, Andersen KN, Sussman E, Carpenter A Jr, Connolly ES (2012) The surgical management of chronic subdural hematoma. Neurosurg Rev 35(2):155-169

8. Dumont TM, Rughani AI, Goeckes T, Tranmer BI (2013) Chronic subdural hematoma: a sentinel health event. World Neurosurg 80(6):889-892

9. Glancz LJ, Poon MTC, Coulter IC, Hutchinson PJ, Kolias AG, Brennan PM, British Neurosurgical Trainee Research Collaborative (2019) Does drain position and duration influence outcomes in patients undergoing burr-hole evacuation of chronic subdural hematoma? Lessons from a UK Multicenter Prospective Cohort Study. Neurosurgery 85(4):486-493

10. Gulati S, Solheim O, Carlsen SM, Øie LR, Jensberg H, Gulati AM, Madsbu MA, Giannadakis C, Jakola AS, Salvesen $\varnothing$ (2018) Risk of intracranial hemorrhage (RICH) in users of oral antithrombotic drugs: nationwide pharmacoepidemiological study. PLoS One 13(8):e0202575

11. Han MH, Ryu JI, Kim CH, Kim JM, Cheong JH, Yi HJ (2017) Predictive factors for recurrence and clinical outcomes in patients with chronic subdural hematoma. J Neurosurg 127(5):1117-1125 
12. Häni L, Vulcu S, Branca M, Fung C, Z'Graggen WJ, Murek M, Raabe A, Beck J, Schucht P (2020) Subdural versus subgaleal drainage for chronic subdural hematomas: a post hoc analysis of the TOSCAN trial. J Neurosurg 133(4):1147-1155

13. Kamenova M, Wanderer S, Lipps P, Marbacher S, Mariani L, Soleman J (2020) When the drain hits the brain. World Neurosurg. https://doi.org/10.1016/j.wneu.2020.02.166

14. Kolias AG, Chari A, Santarius T, Hutchinson PJ (2014) Chronic subdural haematoma: modern management and emerging therapies. Nat Rev Neurol 10(10):570-578

15. Landriel Ibanez FA, Hem S, Ajler P, Vecchi E, Ciraolo C, Baccanelli M, Tramontano R, Knezevich F, Carizzo A (2011) A new classification of complications in neurosurgery. World Neurosurg 75(5-6):709-715

16. Lega BC, Danish SF, Malhotra NR, Sonnad SS, Stein SC (2010) Choosing the best operation for chronic subdural hematoma: a decision analysis. J Neurosurg 113(3):615-621

17. Miranda LB, Braxton E, Hobbs J, Quigley MR (2011) Chronic subdural hematoma in the elderly: not a benign disease. J Neurosurg 114(1):72-76

18. Quan H, Li B, Couris CM, Fushimi K, Graham P, Hider P, Januel JM, Sundararajan V (2011) Updating and validating the Charlson comorbidity index and score for risk adjustment in hospital discharge abstracts using data from 6 countries. Am J Epidemiol 173(6):676-682

19. Rauhala M, Helén P, Seppä K, Huhtala H, Iverson GL, Niskakangas T, Öhman J, Luoto TM (2020) Long-term excess mortality after chronic subdural hematoma. Acta Neurochir (Wien) 162(6):1467-1478

20. Regan JM, Worley E, Shelburne C, Pullarkat R, Watson JC (2015) Burr hole washout versus craniotomy for chronic subdural hematoma: patient outcome and cost analysis. PLoS One. https://doi. org/10.1371/journal.pone.0115085

21. Rohde V, Graf G, Hassler W (2002) Complications of burr-hole craniostomy and closed-system drainage for chronic subdural hematomas: a retrospective analysis of 376 patients. Neurosurg Rev 25(1-2):89-94

22. Santarius T, Lawton R, Kirkpatrick PJ, Hutchinson PJ (2008) The management of primary chronic subdural haematoma: a questionnaire survey of practice in the United Kingdom and the Republic of Ireland. Br J Neurosurg 22(4):529-534

23. Santarius T, Kirkpatrick PJ, Ganesan D, Chia HL, Jalloh I, Smielewski P, Richards HK, Marcus H, Parker RA, Price
SJ, Kirollos RW, Pickard JD, Hutchinson PJ (2009) Use of drains versus no drains after burr-hole evacuation of chronic subdural haematoma: a randomised controlled trial. Lancet 374(9695):1067-1073

24. Sjåvik K, Bartek J Jr, Sagberg LM, Henriksen ML, Gulati S, Ståhl FL, Kristiansson H, Solheim O, Förander P, Jakola AS (2017) Assessment of drainage techniques for evacuation of chronic subdural hematoma: a consecutive population-based comparative cohort study. J Neurosurg. https://doi.org/10.3171/2016.12.JNS16 1713

25. Smith DM, Kishikova L, Norris MJ (2012) Surgical management of chronic subdural haematoma: one hole or two. Int J Surg 10(9):450-452

26. Soleman J, Lutz K, Schaedelin S, Kamenova M, Guzman R, Mariani L, Fandino J (2019) Subperiosteal vs subdural drain after burr-hole drainage of chronic subdural hematoma: a randomized clinical trial (cSDH-Drain-Trial). Neurosurgery 85(5):E825-E834

27. Van Der Veken J, Duerinck J, Buyl R, Van Rompaey K, Herregodts P, D'Haens J (2014) Mini-craniotomy as the primary surgical intervention for the treatment of chronic subdural hematoma-a retrospective analysis. Acta Neurochir (Wien) 156(5):981-987

28. Wan Y, Xie D, Xue Z, Xie J, Song Z, Wang Y, Yang S (2019) Single versus double burr hole craniostomy in surgical treatment of chronic subdural hematoma: a meta-analysis. World Neurosurg. https://doi.org/10.1016/j.wneu.2019.07.097

29. Weigel R, Schmiedek P, Krauss JK (2003) Outcome of contemporary surgery for chronic subdural haematoma: evidence based review. J Neurol Neurosurg Psychiatry 74(7):937-943

30. Zolfaghari S, Ståhl N, Nittby Redebrandt H (2018) Does time from diagnostic CT until surgical evacuation affect outcome in patients with chronic subdural hematoma? Acta Neurochir (Wien) 160(9):1703-1709

31. Zolfaghari S, Bartek J Jr, Djärf F, Wong S, Strom I, Ståhl N, Jakola AS, Nittby Redebrandt H (2021) Risk factors for need of reoperation in bilateral chronic subdural hematomas. Acta Neurochir (Wien). https://doi.org/10.1007/s00701-021-04811-5

Publisher's note Springer Nature remains neutral with regard to jurisdictional claims in published maps and institutional affiliations. 